\title{
Periodismo participativo y Blogs: Desafíos de los nuevos espacios de interacción en la Web
}

\author{
Alejandro MORALES VARGAS* \\ "Internet, más que un red de computadoras, es un red de personas" \\ -John December
}

El domingo 6 de agosto de 2006 se cumplieron los primeros quince años desde que en Ginebra, Suiza, el físico británico Tim Berners-Lee del Laboratorio Europeo de Física de Partículas (CERN), desarrollara la World Wide Web (WWW), interfaz gráfica que permitiría masificar el uso de la hasta ese entonces intrincada e inexpugnable red mundial de computadores conectados llamada Internet. Más allá de lo significativo y relevante de esta fecha para la sociedad contemporánea y el fenómeno de la globalización, lo anecdótico fue el método utilizado por el científico para difundir la invención: publicó su código fuente en ciernes en un boletín de noticias distribuido vía electrónica para que los demás profesionales suscritos desde todas partes del mundo pudieran experimentar con éste y entregarle retroalimentación. En aquel sencillo hecho, Barners-Lee parece haber profetizado el espíritu colaborativo que en la actualidad comienza a imperar en la red y donde ya no son los usuarios lo que van a los medios para mantenerse al día, sino que seleccionan y reciben las informaciones de su interés directamente en sus casillas de correo, con la posibilidad de modificarlas y comentarlas.

En estos años de evolución de internet, se ha verificado el paso de una red de redes o "supercarrertera de la información" a un poderoso medio de comunicación masivo y legitimado socialmente, soporte de una extensa variedad de sitios de noticias confeccionadas exclusivamente para la web, con la misma rigurosidad que en los medios tradicionales, pero con mayor potencial, impacto y alcance. Basta tan sólo pensar en cómo esta "nueva" tecnología ha moldeado la llamada Sociedad de la Información y ha transformado la labor de los periodistas, consolidando el periodismo digital como una importante especialidad de la disciplina, tema que hoy en día ya nadie discute.

No obstante, en dicho proceso se observa también un fenómeno menos estudiado y que se relaciona con el importante cambio acaecido en el comportamiento de los usuarios en cuanto a su nivel de interacción con la web y de dominio de los aspectos técnicos involucrados en su desarrollo, constatándose una creciente demanda por ocupar nuevos espacios y desempeñar un papel distinto frente a la red.

Conforme se ha amplificado el acceso y la conectividad, han variado también las expectativas de los internautas frente a los productos informativos que esperan recibir por parte de la prensa digital y el rol que les corresponde desempeñar frente a éstos, entendiendo, por ejemplo, que actualmente los medios online, al igual que cualquier otro sitio web, ya no son valorados tanto por lo que publican, sino por lo que hacen o dejan hacer.

Un factor clave que ha impulsado este cambio es el advenimiento de nuevas herramientas de publicación electrónica, como los CMS (Content Management Systems) o

\footnotetext{
* Periodista y Licenciado en Comunicación Social de la Universidad de Chile. Académico del Instituto de la Comunicación e Imagen de la misma casa de estudios.
} 
sistemas de gestión y administración de contenidos en línea, que ya no hacen indispensable el dominio del críptico lenguaje HTML (HyperText Markup Language) con que se programaban las primeras páginas web o el uso de software especializados altamente complejos para subir textos a Internet. En la actualidad, cualquier usuario con conocimientos básicos, similares a los requeridos para enviar un e-mail, puede publicar contenidos en su propio sitio.

Pueden distinguirse, entonces, tres etapas o estadios de los navegantes frente a los medios electrónicos. En la primera, los usuarios sólo leen diarios electrónicos cuya única novedad frente a las versiones tradicionales es el soporte, que transita del papel a la web. En este nivel se encuentran aún muchos sitios en los cuales predominan grandes volúmenes de textos planos, sin atributos gráficos ni hipertextuales ${ }^{1}$, y que se confeccionan con las mismas lógicas y vicios de las publicaciones impresas.

En una segunda etapa, iniciada a fines de la década pasada e inicios de la presente, los usuarios ya no se sientan frente a un monitor como espectadores pasivos en un cine o lectores de un libro, sino que experimentan los medios digitales, conjugando múltiples verbos mientras navegan, como por ejemplo, observar, escuchar, buscar, descargar, comentar, consultar, jugar y comprar. Aquí, tantos los usuarios como los editores valoran la inmediatez e instantaneidad en la actualización de las informaciones, la confección de productos multimediales que integren audio, fotografía y video, y la posibilidad de ofrecer espacios de opinión y participación, como los chats, foros de discusión, encuestas y formularios de contacto con las redacciones.

La tercera, en la cual nos encontramos en la actualidad, es la etapa de la interacción, entendida como la posibilidad de efectuar cambios en la información presentada ${ }^{2}$, en donde los usuarios crean y mantienen sus propios medios de comunicación en Internet, consolidándose un perfil activo y opinante en ellos. En este estadio proliferan las populares bitácoras o blogs, el podcast (transmisión de audio en línea) y los vlogs (blogs de videos), y emergen conceptos como el llamado periodismo participativo y la publicación colaborativa, en donde son las mismas audiencias las que alimentan de información los medios electrónicos, "democratizando" el acceso a la pauta informativa y rescatando el valor de las noticias locales por sobre las globales.

Además, gracias a la tecnología de redifusión o sindicación de contenidos RSS (Really Simple Syndication), para los usuarios ya no es necesario "ir" a los medios a recolectar informaciones, abriendo múltiples páginas web, sino que los textos sobre temas preseleccionados llegan directamente a un programa ad hoc del computador ${ }^{3}$ denominado "agregador" o feeds reader. Con ello, queda en manos de los usuarios la selección de su propio menú informativo, observándose una deconstrucción de las jerarquías visuales y narrativas implicadas en la diagramación de un espacio web.

\section{Nosotros, el medio}

En 1995, en su libro "Ser digital", el académico estadounidense Nicholas Negroponte, director del MediaLab del Massachusetts Institute of Technology (MIT) y fundador de la revista Wired, predijo que en el futuro las noticias en línea darían a los

\footnotetext{
${ }^{1}$ FIEBICH, Christina y PAUL, Nora. The elements of digital storytelling. School of Journalism and Mass Communication's Institute for New Media Studies. University of Minnesota. 2005. En línea: http://www.inms.umn.edu/elements (consultado: 05/09/2006)

${ }^{2}$ SALAVERRÍA, Ramón. Redacción periodística en internet. Eunsa. España. 2005. Pág. 22

${ }^{3}$ PISCITELLI, Alejandro. Internet, la imprenta del Siglo XXI. Gedisa. España. 2005. Pág. 75
} 
lectores la habilidad para escoger solos los temas y las fuentes de información que les interesaran:

"¿Qué tal si un diario estuviese dispuesto a poner todo su plantel de periodistas a sus órdenes, para que le preparen una edición a su medida? Mezclaría los titulares del diario con notas menos importantes relacionadas con gente que usted conoce, gente que verá mañana y lugares que está por visitar o que visitó recientemente. Informaría sobre empresas que usted conoce. De hecho, bajo estas condiciones, es posible que usted esté dispuesto a pagarle a su diario mucho más por diez páginas personalizadas que lo que paga ahora por cien páginas. Estaría seguro de recibir exactamente la información que usted necesita". 4

A su visión la llamó "El diario mío" ("The daily me") y despertó la inmediata alerta de los garantes del periodismo tradicional, que vieron en este panorama una amenaza a la función histórica de selección, evaluación y edición de las informaciones.

Transcurridos más de diez años de este anuncio de Negroponte, lo que parecía ciencia ficción se está haciendo realidad de la mano de un nuevo movimiento dentro del periodismo conocido como "Nosotros, el medio" ("We media") $)^{5}$, inspirado en el libro homónimo que en el 2003 redactaran los investigadores Shayne Bowman y Chris Willis para el American Press Institute, un informe sobre cómo las audiencias están modelando el futuro de las noticias y la información en la red.

Para los autores, la profesión del periodismo se encuentra en un momento de la historia donde, por primera vez, su hegemonía como "guardián de las noticias es amenazada no solo por la tecnología y los nuevos competidores, sino, potencialmente, por la audiencia a la que sirve. Armada con herramientas de edición web fáciles de usar, conexiones permanentes y dispositivos móviles cada vez más potentes, la audiencia en línea tiene los medios para llegar a ser un activo participante en la creación y diseminación de noticias e información. Y está haciendo eso en Internet" ${ }^{\text {" }}$

A modo de ejemplo, el estudio cita entre las primeras muestras de este fenómeno emergente el que los ciudadanos estadounidenses hayan acudido a medios de comunicación interpersonales, como los correos electrónicos, los foros o los incipientes blogs, para obtener información sobre los atentados terroristas del 11 de septiembre de 2001, ante el colapso de los principales sitios de noticias en línea. Lo propio ocurrió durante las manifestaciones previas a la invasión a Irak, donde las audiencias dieron mayor credibilidad a lo publicado en bitácoras de los ciudadanos residentes de las principales capitales del mundo, por sobre lo informado en los medios tradicionales, al punto que la propia BBC News pidió a sus lectores que enviaran imágenes tomadas con cámaras digitales ante la imposibilidad de cubrir todas las concentraciones organizadas.

Lo que asoma como un eventual factor de crisis para la concepción clásica de distribución de las noticias, para los seguidores de "Nosotros, el medio" no es más que devolver a la ciudadanía reales espacios de participación en la esfera pública, abriendo el acceso a la generación y jerarquización de mensajes. De igual modo, la ampliación de la pauta informativa a nuevos actores y nuevos temas, contribuye a la diversidad y el pluralismo que requieren las sociedades para el fortalecimiento de la democracia.

\footnotetext{
${ }^{4}$ NEGROPONTE, Nicholas. Ser digital. Pág. 159. Editorial Atlántida. Argentina. 1995

${ }^{5}$ BOWMAN, Shayne y WILLIS, Chirs. Nosotros, el medio: Cómo las audiencias están modelando el futuro de las noticias y la información. The Media Center at The American Press Institute. Estados Unidos. 2003 En línea: http://www.hypergene.net/wemedia (Consultado: 23/11/2005)

${ }^{6}$ BOWMAN, Shayne y WILLIS, Chirs. Op. Cit. Pág. 7.
} 
A juicio de uno de sus principales precursores, el periodista estadounidense Dan Gillmor $^{7}$, los postulados o premisas fundamentales de esta tendencia se entienden al asumir que esto no es una amenaza sino una oportunidad y que, pese a la sólida preparación profesional que puedan tener los periodistas, siempre "mis lectores saben más que yo".

\section{Ciudadanos-reporteros}

Aunque por definición la labor periodística alude a la idea de lo público y la relación con la gente, las iniciativas registradas en el mencionado informe, entre otras, han consolidado un concepto que si bien no nace con las nuevas tecnologías, ha visto en éstas el motor que le faltaba para despegar. Se trata del periodismo participativo, periodismo ciudadano o periodismo 3.0 (recogiendo la nomenclatura con que se designan las diferentes versiones de un software).

En la definición de Bowman y Willis, se trata del "acto de un ciudadano o grupo de ciudadanos que juegan un papel activo en el proceso de colectar, reportar, analizar y diseminar información. La intención de esta participación es suministrar la información independiente, confiable, exacta, de amplio rango y relevante que una democracia requiere". 8

Así, si en la concepción tradicional el esquema de distribución de informaciones es lineal y unidireccional, donde a través de los medios de comunicación masivos los periodistas se dirigen a una audiencia heterogénea, en la visión del periodismo participativo la comunidad es emisora y receptora de los mensajes a la vez, con presencia en todas las instancias de la cadena (ver figura 1). A este modelo el proyecto "Nosotros, el medio" lo denomina interconexión, en donde las noticias van "de abajo hacia arriba".

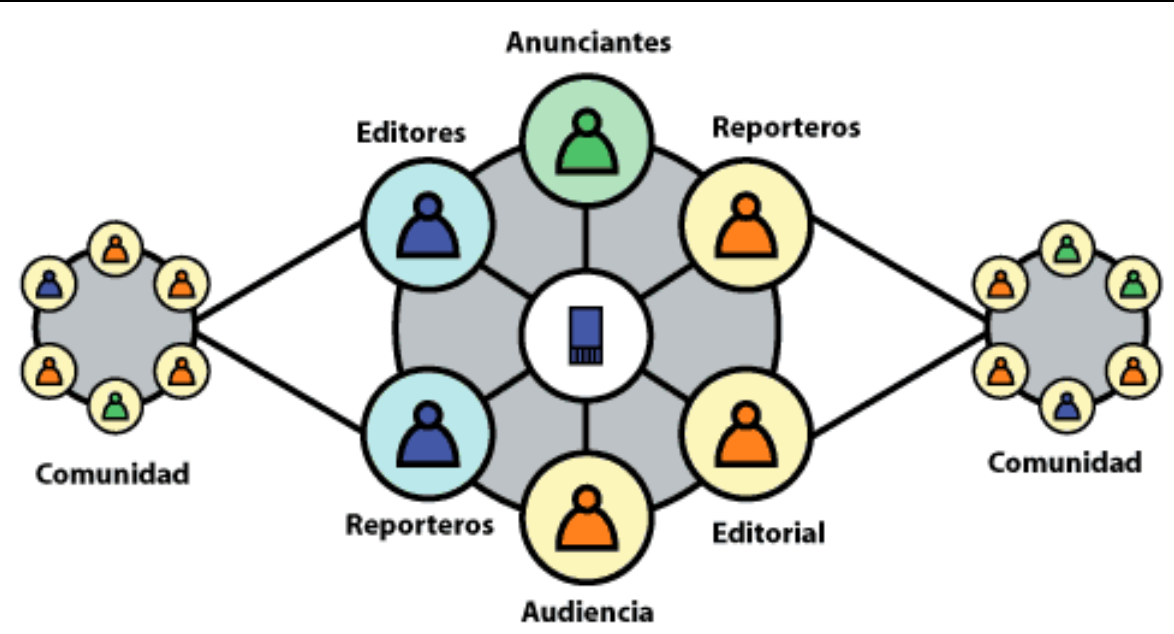

Figura 1. Modelo de interconexión, en esquema de "Nosotros, el medio"

\footnotetext{
${ }^{7}$ Dan Gillmor fue redactor del diario San José Mercury News y es el actual director del Center for Citizen Media, un proyecto de investigación desarrollado por el Berkman Center for Internet \& Society de la Harvard University y la Graduate School of Journalism de la University of California-Berkeley. Es autor autor del texto "We the media: Grassroots journalism by the people, for the people" (Nosotros el medio: las raíces del periodismo, por la gente y para la gente). O'Reilly Media, Estados Unidos, 2004. Su sitio web personal es http://www.dangillmor.com (consultado: 06/09/2006)

${ }^{8}$ BOWMAN, Shayne y WILLIS, Chirs. Op. Cit. Pág. 9.
} 
El ejemplo más usado para graficar esta interconexión es el diario surcoreano OhmyNews ${ }^{9}$, convertido ya en el ícono del periodismo participativo a nivel mundial, pues es alimentado con noticias provistas por ciudadanos-reporteros de todo el mundo, sin que se les exija estudios de Periodismo. Cuenta más de 35.000 colaboradores en todo el orbe y un equipo de medio centenar de periodistas profesionales que editan y publican los textos en los diferentes idiomas del medio (coreano, inglés y próximamente japonés), cuyas páginas reciben más de 15 millones de visitas diarias. Fue fundado en el año 2000 por Oh Yeon Ho, quien comentó en una de las pocas entrevistas concedidas que su propósito era "decir adiós al periodismo del siglo XX en el que la gente sólo veía las cosas a través de los medios conservadores (...) Nosotros publicamos todo y la gente juzga la verdad por ella misma"10, según reproduce el blog de María Pastora Sandoval, la primera chilena en reportar noticias periódicamente para dicho diario asiático y percibir remuneraciones por ello.

En Chile también se están realizando experiencias de este tipo, las que funcionan bajo el alero del movimiento Atina Chile, principalmente como proyectos de carácter regional. El primer diario participativo desarrollado en español ${ }^{11}$ se llama "El Morrocotudo" $"$, con sede en Arica, pero tiene más de 400 corresponsales en toda la I Región de Tarapacá, entre otros lugares. Su esquema de edición opera de manera similar a la de su par surcoreano, en cuanto brinda la posibilidad a los ciudadanos de enviar noticias, fotografías y enlaces relacionados, los cuales pasan por un equipo editor que evalúa la calidad del material, la variedad y confiabilidad de sus fuentes antes de publicar en cualquiera de las secciones temáticas del web. Además, permite a los lectores escribir comentarios y valorar cada contenido, de manera tal de enriquecer el texto final.

A esta iniciativa se han sumado otros diarios electrónicos, como el caso de "El Rancahuaso"13 de la VI Región del Libertador Bernardo O'Higgins y "El Amaule"14 de la VII Región del Maule. Si bien el contexto en el cual surgen estos medios está orientado justamente a poner de relieve el valor de las noticias regionales, esta no es una situación aislada en el contexto del desarrollo mundial de la prensa en la red. Cada vez con más frecuencia se observa la paradoja de que, en pleno proceso de globalización y frente a la posibilidad de conexión internacional que ofrece Internet en cosa de segundos, las noticias de carácter local y hasta cotidiano están adquiriendo un valor predominante. Ya lo decía la ex directora de operaciones del diario estadounidense The Miami Herald, Janine Warner, en una entrevista con el autor el 2003 al señalar que nunca su sitio web recibió más visitas que durante el caso del niño cubano Elián González. "Si bien todos los medios del mundo tenían la noticia, la gente quería saber cómo la informábamos nosotros que sí estábamos en Miami”, sostuvo.

Si bien algunos postulados del periodismo participativo pudiesen leerse como un punto de crisis para las fórmulas conocidas o generar tensión en la definición del rol del

\footnotetext{
${ }^{9}$ OhmyNews International. En línea: http://english.ohmynews.com (consultado: 28/05/2006)

${ }^{10}$ E-dentidad, blog de María Pastora Sandoval Campos. En línea: http://www.mariapastora.cl/2005/09/08/ohmynews-en-las-ultimas-noticias (consultado: 06/09/2006)

${ }^{11}$ DOMINGUEZ, Jorge. "Yo tengo un medio": Los blogs y el periodismo participativo. En Revista Universitaria. No 90, Marzo-mayo, 2006. En línea: http://www.uc.cl/ru/90/html/dossier4.htm (consultado: 06/08/2006)

${ }^{12}$ El Morrocotudo, el diario nuestro de cada día. En línea: http://www.elmorrocotudo.cl (consultado: (05/09/2006)

${ }^{13}$ El Rancahuaso, nuestro diario vivir. En línea: http://www.elrancahuaso.cl (consultado: 05/09/2006)

${ }^{14}$ El Amaule, un diario como usted. En línea: http://www.elamaule.cl (consultado: 05/09/2006)
} 
profesional de las comunicaciones en la sociedad, la existencia de instancias de edición por parte de periodistas en medios como los mencionados, distinguiendo claramente la función del reportero respecto a la del editor, garantiza de alguna manera el debido resguardo de la calidad informativa $\mathrm{y}$, sobre todo, la ponderación a la luz de valores fundamentales del ejercicio como la ética y la libertad de expresión.

Sin embargo, la situación no es igual en todos los nuevos espacios de interacción en la red, existiendo casos donde los desafíos para el periodismo son aún mayores.

\section{La voz de la blogósfera}

Catalogado como el concepto más popular en Internet hoy en día, la bitácora personal en línea, weblog, o, simplemente, blog, es por definición una publicación individual o grupal de la web en las que, de manera cronológica, pero sin periodicidad establecida, el autor o los autores publican comentarios, notas o artículos. Estos textos, conocidos como posts en la jerga weblogger, suelen incluir enlaces, y también eventualmente imágenes y otros contenidos multimedia. Asimismo, es frecuente que ofrezcan espacios para el comentario, donde los lectores puedan expresar libremente sus opiniones y observaciones acerca de cada una de las notas ${ }^{15}$.

Si bien no hay consenso en cuál fue el primero, entre 1993 y 1994 se reportan las primeras manifestaciones de weblogs, aunque el término no es acuñado sino hasta 1997 por Jorn Barger ${ }^{16}$, cuando definió sus elementos constitutivos. Pero más allá de estas fechas, lo importante es que en menos de una década han proliferado por la red con una velocidad nunca antes experimentada por otra aplicación de la web: nada menos que a una tasa de 175.000 al día. Es decir, ¡más de dos blogs nuevos cada segundo!

Según estas cifras publicadas por Technorati ${ }^{17}$, el principal buscador especializado en bitácoras del mundo, el 31 de julio de 2006 se alcanzó los 50 millones de este tipo de páginas web personales registradas, con lo cual la "blogosfera" (como se le denomina a la comunidad articulada bajo los blogs) es 100 veces más grande que hace tres años y su número se duplica cada seis meses aproximadamente. A ese ritmo, según David Sifry, el creador del buscador, en febrero de 2007 habría 100 millones de blogs en todo el mundo. ${ }^{18}$

Si bien en su naturaleza primera constituían una suerte de diario de vida personal, donde principalmente se consignaban comentarios y se repetía sobre éstos un modelo conversacional, la facilidad con que se pueden publicar y actualizar sus textos (ya que están basados en un sistema gestor de contenidos gratuito del tipo CMS que no requiere conocimientos técnicos avanzados por parte de los usuarios), le abrió rápido camino para diversificar su uso y constituirse en una oportunidad de valor agregado para el periodismo.

$\mathrm{El}$ advenimiento de esta herramienta permite, entre otros, que los periodistas puedan tener sus propios medios de comunicación a costos de producción muchas veces iguales a cero, pudiendo renovar su información desde cualquier lugar del mundo con conexión y en todo horario. Por su parte, permite a las empresas periodísticas recoger con extraordinaria inmediatez el "pulso" de lo que opina, libremente y en primera persona, la ciudadanía frente a ciertos temas, traspasando las barreras espacio-temporales de todas las mediciones de audiencia.

\footnotetext{
${ }^{15}$ SALAVERRÍA, Ramón. Op. Cit. Pág. 155.

${ }^{16}$ DOMINGUEZ, Jorge. Op. Cit.

${ }^{17}$ Technorati. En línea: http://www.technorati.com (consultado: 05/09/2006)

${ }^{18}$ Sifry's Alerts. En línea: http://www.sifry.com/alerts/archives/000436.html (consultado: 05/09/2006)
} 
La estrecha relación entre los blogs y el periodismo puede establecer ante la pregunta ¿sobre qué escribe la gente en las bitácoras personales? Respuesta: mayoritariamente sobre hechos noticiosos. Ello se demuestra al cruzar la información sobre el aumento de comentarios o posts en los últimos años con las fechas en que han ocurrido acontecimientos de relevancia mundial, como el tsunami en las costas sudasiáticas, los atentados con bombas en Londres, el huracán Katrina o el conflicto entre Israel y Hizbulá, hitos en los cuales se aprecia un importante aumento sobre el promedio de artículos nuevos diarios, que actualmente equivale a 1,6 millones (ver figura 2).

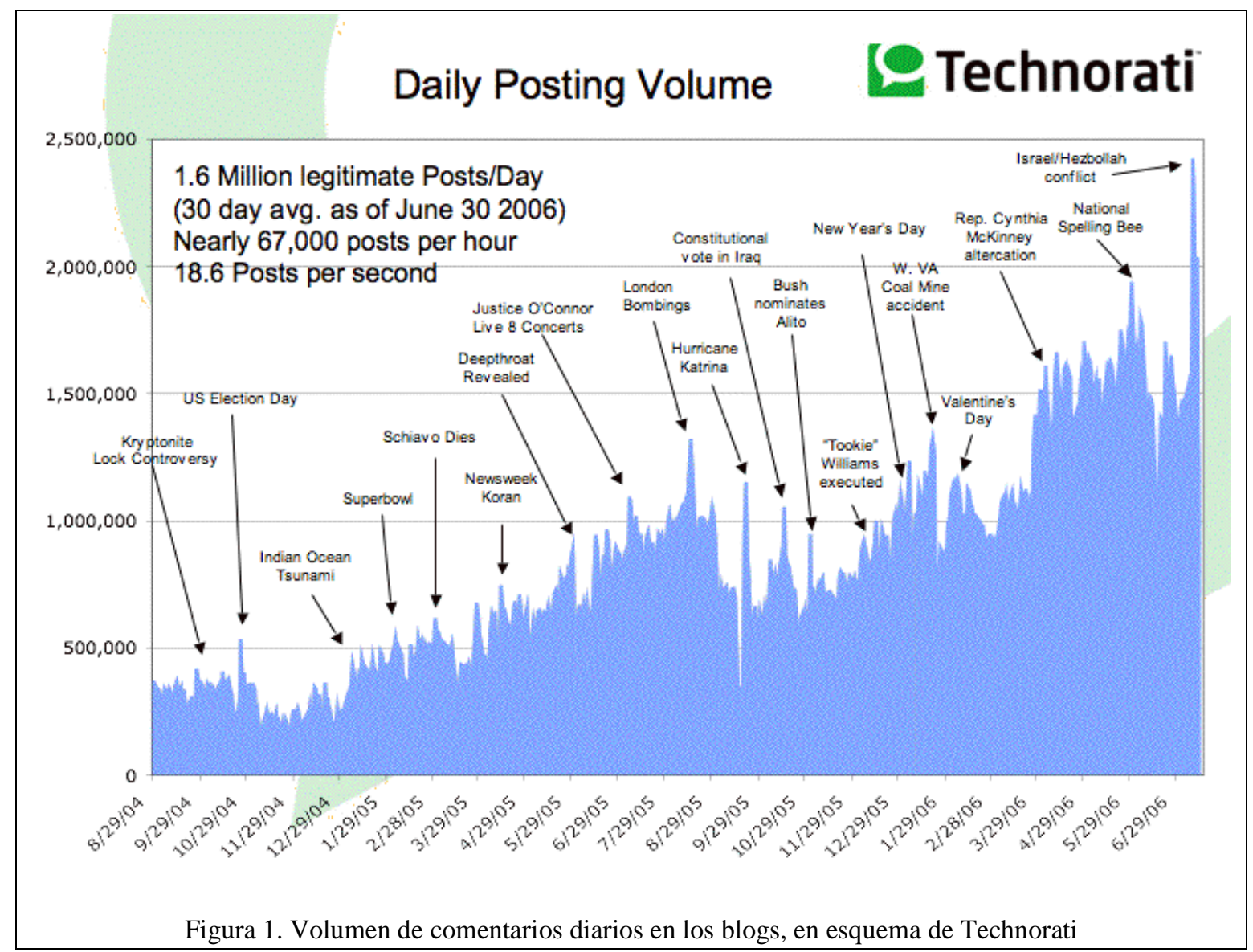

No obstante, esta relación no está exenta de tensiones. Fue durante la cobertura del conflicto en Irak, en noviembre de 2004, cuando comenzaron las primeras fricciones entre las bitácoras personales y el periodismo tradicional. Mientras colaboraba para las cadenas, CNN y NBC, el periodista Kevin Sites liberó en su blog ${ }^{19}$ material que mostraba a marines de Estados Unidos disparándole a un iraquí desarmado. También fue uno de los primeros en romper el bloqueo de imágenes de soldados norteamericanos muertos, por lo que pasó a ser el primero de muchos periodistas que han perdido su empleo a causa de sus blogs. El hecho, que en lo personal para Sites significó el reconocimiento mundial por su defensa de la libertad de expresión y el derecho a la información (y un contrato como asesor de Yahoo! sobre estos temas), instaló el conflicto latente que emerge cuando estas nuevas tecnologías

${ }^{19}$ Kevin Sites Blog. En línea: http://www.kevinsites.net (consultado: 07/06/2006) 
se sitúan entre el imperativo ético y de veracidad de los profesionales de la prensa, y los intereses de los medios donde se desempeñan habitualmente.

Del mismo modo, surgen nuevas interrogantes de la práctica profesional con los weblogs: ¿puede un periodista publicar en su blog personal información que ha obtenido reporteando para un medio tradicional? ¿de quién son los derechos de autor? ¿cómo puede garantizarse la libertad de expresión en estos nuevos medios en el caso que existan diferencias entre lo que publican los periodistas en sus bitácoras web con las líneas editoriales de las empresas donde laboran regularmente?

$\mathrm{Al}$ respecto de la propiedad intelectual, "como regla general, el periodista no puede usar la información adquirida reporteando en su blog personal sin autorización, salvo que lo haga después de su publicación y citándola como fuente, como podría hacerlo cualquier otra persona. Los derechos de autor (en su aspecto económico) son de la empresa, salvo pacto en contrario" 20 . No obstante, el académico y abogado Pedro Anguita plantea que no debemos olvidar que el derecho a opinar y a informar que tienen los periodistas se podría ver menoscabado en el caso que se apartara de la línea del medio, ocasión en la cual hay que hacer una distinción, "porque una cosa es desempeñar funciones y seguir los lineamientos de los dueños y editores, y otra es que los periodistas no puedan ejercer sus derechos constitucionales como el resto de los ciudadanos" 21 .

Es por ello que, como una forma de flexibilizar el tradicional derecho de autor o copyright y poder operar en la "blogósfera" sobre la base de un espíritu colaborativo, es muy común que los "blogueros" licencien los contenidos de sus bitácoras bajo modelos alternativos o complementarios de propiedad intelectual, como es el caso del sistema Creative Commons ${ }^{22}$, orientado a entregar una amplia gama de niveles de uso que un autor desee otorgar a la comunidad sobre su obra, los que van desde el acceso libre y dominio público hasta rangos más restrictivos. Es lo que se conoce como "copyleft". En Chile esta modalidad debutó en julio de 2005, patrocinado por la Universidad de Chile y la Corporación Derechos Digitales, una organización no gubernamental que ha desarrollado además la Guía legal del blogger ${ }^{23}$, que brinda asesoría jurídica respecto a las condiciones de la información publicada en estos nuevos medios.

\section{Filosofía wiki}

Como se ha analizado, la posibilidad de masificación de las herramientas de interacción en la web abre el debate de la ética profesional, la veracidad y calidad de la información. Desde el punto de vista práctico no existen mecanismos de control posible ante tal volumen de datos ni es necesariamente deseable que los haya. En ese contexto, la fórmula utilizada por los "wikis" o sistemas de redacción colaborativa surgen como una interesante respuesta, ya que funcionan sobre la base del concepto de "inteligencia repartida" en la cual la suma de los conocimientos de muchos usuarios en la red es más edificante que el de una sola persona.

\footnotetext{
${ }^{20}$ Consultorio de Ética Periodística. Universidad Diego Portales. En línea:

http://www.udp.cl/comunicacion/periodismo/consultorioetica/temas/blog.htm (consultado: 27/08/2006)

${ }^{21}$ Ibíd.

22 Creative Commons Chile. SISIB - Universidad de Chile y Corporación Derechos Digitales. En línea: http://www.creativecommons.cl (consultado: 05/09/2006)

${ }^{23}$ Guía Legal del Blogger. Corporación Derechos Digitales. En línea: http://www.derechosdigitales.org/glb/ (consultado: 05/04/2006)
} 
Por ejemplo, la Wikipedia ${ }^{24}$, la popular enciclopedia libre de internet, permite que todos los internautas puedan ingresar definiciones y editar las existentes, de manera tal de llegar a un producto informativo "de consenso" y susceptible de ser enriquecido permanentemente. Según su cofundador, Jimmy Wales, esta plataforma constituye "un esfuerzo para crear y distribuir una enciclopedia, de la más alta calidad posible, a cada persona del planeta, en su idioma, para lograr un mundo en el que cada persona del planeta tenga acceso libre a la suma de todo el saber de la humanidad".

Actualmente tiene ediciones en 229 idiomas y almacena más de 3.800 .000 artículos, pero ¿quién controla la calidad de los mismos? Según se declara en su propio sitio, la Wikipedia fue creada con la idea de que la colaboración entre usuarios por la mejora de un artículo durante un tiempo producirá textos de calidad, a semejanza de los proyectos de desarrollo de aplicaciones libres o de código abierto. Así, los artículos evolucionan a través del tiempo y esto es visible en su historial de ediciones. No en vano, un estudio de la prestigiosa revista científica Nature $^{26}$, estableció que casi iguala en calidad a la Enciclopedia Británica, tras comparar las definiciones de 42 de conceptos, encontrándose sólo 162 errores en el proyecto online frente a 123 en la tradicional fuente de información de habla inglesa.

En este contexto, se puede afirmar que las nuevas tecnologías de interacción y el periodismo participativo llegaron para quedarse y constituyen una oportunidad para involucrar a más actores sociales en el proceso de transmisión de mensajes. Sin embargo, como lo demuestra la "filosofía wiki", su valor intrínseco sigue residiendo no en el medio sino en la calidad del contenido.

Por ende, para el caso de las noticias y el ejercicio del periodismo en general, la irrupción de estas nuevas herramientas, si bien instala un nuevo escenario de retroalimentación con las audiencias y el acto de publicar se "democratiza", en nada hace variar el papel del periodista como profesional que informa, interpreta y opina en la sociedad con criterios de precisión y calidad, ni, menos aún, hace bajar la guardia frente a los estándares de calidad, la veracidad y el compromiso con la ética.

\section{Referencias bibliográficas}

BOWMAN, Shayne y WILLIS, Chirs. Nosotros, el medio: Cómo las audiencias están modelando el futuro de las noticias y la información. The Media Center at The American Press Institute. Estados Unidos. 2003.

CEBRIÁN, Juan Luis. La red: cómo cambiarán nuestras vidas los nuevos medios de comunicación. Editorial Taurus. España. 1998.

NEGROPONTE, Nicholas. Ser digital. Editorial Atlántida. Argentina. 1995.

ORIHUELA, José Luis. La revolución de los blogs. Cuando las bitácoras se convirtieron en el medio de comunicación de la gente. La Esfera de los Libros. España. 2006.

PISCITELLI, Alejandro. Internet, la imprenta del Siglo XXI. Gedisa. España. 2005.

SALAVERRÍA, Ramón. Redacción periodística en internet. Eunsa. España. 2005.

\footnotetext{
${ }^{24}$ Wikipedia, La enciclopedia libre. En línea: http://es.wikipedia.org (consultado: 28/05/2006)

${ }^{25}$ Ibíd.

26 “Internet encyclopaedias go head to head", en Nature vol. 438, No 7070, 2005, En línea:

http://www.nature.com/nature/journal/v438/n7070/full/438900a.html (consultado: 07/09/2006)
} 